\title{
Smart Specialisation 2.0: Driving Public Funds Towards Platforms and Ecosystems
}

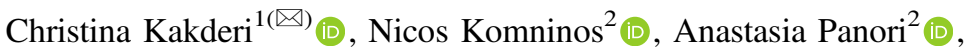 \\ and Artemis Psaltoglou ${ }^{2}$ (D) \\ 1 Aristotle University, Thessaloniki 54124, Greece \\ kakderi@plandevel.auth.gr \\ ${ }^{2}$ URENIO Research, PO Box 491, 54124 Thessaloniki, Greece
}

\begin{abstract}
The paper negotiates two main questions of the methodology of EDP in Smart Specialisation. First is the granularity level of detail in the analysis and the assessment of dynamism of economic activities. We argue that NACE threedigit codes offer the best combination of homogeneity of statistics and sectoral studies. Still, all NACE three-digit codes are not cadets for discovering business opportunities and new innovation activities and therefore, further research for the selection of priority fields is necessary. Second question is about the collective nature of interventions and investments developed through EDP. We argue that business ecosystems that unite large number of enterprises may exceed the risk of priority investments for specific businesses and groups. The demarcation of investments in relation to platform-based ecosystems as well as of ecosystems which are developed on top of value chains is of particular importance. Both methodological principles which are proposed in the paper (selection of three-digit NACE code ecosystems and platforms based on functions/needs of such ecosystems) can complement the theoretical weaknesses that reasonably exist in terms of discovery and innovation.
\end{abstract}

Keywords: Smart specialisation $\cdot$ Platforms $\cdot$ Platform ecosystems · Investment priorities $\cdot$ Entrepreneurial discovery process

\section{Introduction}

In Europe, Smart Specialisation emerged as a leading political instrument of cohesion policy during the 2014-2020 programming period (Foray 2014; McCann and OrtegaArgiles 2015). The overall objective of RIS3 is to create innovative, but place specific and evidence-based capabilities, which take advantage of available resources and competences within a process of diversification and transformation. In particular, diversification and industrial transformational strategies should foster cross-sectoral links and/or cross-border cooperation (Landabaso 2014). These capabilities have to be identified and revealed through an Entrepreneurial Discovery Process, in short

This research is part of the TREnD project (Transition with Resilience for Evolutionary Development), which has received funding from the European Union's Horizon 2020 research and innovation program under the Marie Skłodowska-Curie grant agreement No. 823952.

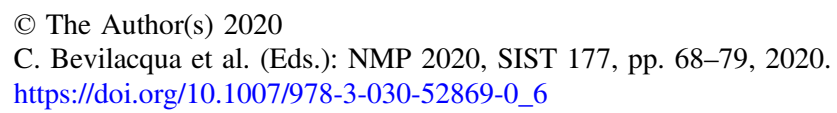


EDP. This new policy instrument was embraced and massively implemented by European regions (Foray 2019) despite the conceptual misunderstandings and difficulties in operationalisation. Today, both the policy and the core principles remain valid and regions will have to repeat this exercise for 2021-2027 since smart specialisation remains a core element of the next period of cohesion policy.

A core element of Smart Specialisation Strategies (S3) which drive the European Structural Investment Funds (ESIF) in European cities and regions is the Entrepreneurial Discovery Process (EDP). The EDP, which is considered the cornerstone of smart specialization (Kyriakou et al. 2017), aims to highlight areas of the regional economy that offer the highest potential for future development and to deal with the difficult problems of selecting and hierarching investment priorities and of allocating the ESIF to specific priorities. During the EDP business stakeholders enter a government-led participatory process and a collaborative dialogue that integrates their fragmented and dispersed knowledge, setting common priorities for intervention and investments for growth. The existence of such an open participatory process together with the use of reliable data, guarantee that the selection of priorities will not be defined based on the interests of specific stakeholders and the region will not lock-in to traditional activities.

Guidance on Entrepreneurial Discovery Process (EDP) was provided by the RIS3 Guide and other official documents on aims, contribution to prioritisation, and methods of implementation.

- EDP "aims to build a systematic understanding of the areas in the economy and society that have the greatest potential for future development" (p. 20) \& "mobilise talent by matching RTD + I capacities and business needs through an entrepreneurial discovery process" (p. 17).

- "Smart Specialisation should address the difficult problem of prioritisation and resource allocation based on the involvement of all stakeholders in a process of entrepreneurial discovery, which should secure a regionally and business-driven, inclusive and open prioritisation process" (p. 52).

- "There are different methodologies for organising such processes, e.g. surveys, seminars with participatory leadership methods, crowdsourcing, etc. Such an open, participatory process, together with reliance on robust evidence based on regional assets, are the best guarantees to avoid both the risk of capture by interest groups and the risk of lock-in into traditional activities" (p. 52). "An effective appreciation of dynamic EDP can only be performed if entrepreneurial actors and management and governance bodies responsible of RIS3 engage in direct discussion” (p. 20).

Despite the guidance provided, serious gaps and open questions still remain in the theory and methodology guiding EDP (Komninos et al. 2018). Related variety offers a reference framework, but not the methodological background for the choice of related or unrelated specialisation and, afterwards, for the selection of investments within priorities' activities. These questions come again to the front, as regions have to initiate a stage (or wave) 2.0 of smart specialisation, this time focusing more on interregional cooperation and good governance (CoR 2018). The S3 in the next programming period will focus on a number of enabling conditions, for good governance, such as (1) Analysis of challenges including bottlenecks for innovation diffusion, (2) Existence 
of competent regional/national institution or body, responsible for the management of the smart specialization strategy, (3) monitoring and evaluation tools to measure performance towards the objectives of the strategy, (4) Functioning of stakeholders cooperation (entrepreneurial discovery process), (5) Actions necessary to improve national or regional research and innovation systems, (6) Support industrial transition, and (7) Actions for internationalization.

The next section provides a short review of the current literature presenting the background of RIS3 implementation and existing challenges. The third section is an analysis of the methodology used for a survey on ecosystems in Greek NUTS-2 regions while the last section provides a discussion of the survey's results and also gives some policy recommendations for the future programming period.

\section{Smart Specialisation in Practice: Past Challenges and Future Questions}

The Research and Innovation Strategy for Smart Specialisation (RIS3) requires EU regions to leverage private research and innovation expenditure towards a limited set of priorities. Such priorities are "areas of investment which regional or national authorities identify as 'key', in order to build competitive advantage by developing and matching research and innovation own strengths to business needs and to address emerging opportunities and market developments in a coherent manner" (Official Journal of the EU 2013). Selection of priority areas is viewed as a process of entrepreneurial discovery through a permanent process of navigation, continuous monitoring and adjustments (Foray 2019).

Achieving an effective prioritisation through EDP has proven to be a challenging task, undermined by a number of issues, among which is the weak understanding of the S3 concept (confusion between prioritisation of industry sectors and clusters or on technological specialisation, KETs and value chains) (Reid et al. 2012; Komninos et al. 2014; Iacobucci 2014); the translation of theoretical guidelines and methodologies into practice (e.g. the identification of technological priorities in peripheral areas with low level of patents (Griniece et al. 2017; Panori et al. 2017; Gianelle et al., 2019); the actual process of prioritisation (the dilemma of diversification, i.e. the identification and selection of tradjectories for future related diversification) (Boschma 2017; Balland et al. 2019); the existence of bottlenecks in the selection of priorities due to different institutional settings and governance capacities (with EDPs leading to lock-in) (Kroll 2015; Hassink and Gong 2019) and the fulfilment of the EC's ex-ante conditionalities (lack of consistency, no clear demarcation between the national, macro-regional, and regional scope of action and responsibility) (Piatkowski et al. 2014). The effectiveness of prioritisation has also been linked to 'the governance of RIS3', i.e. the elements in the institutional setting, the organisation and processes of RIS3 which contribute to the improvement of RIS3 management, monitoring and evaluation, the effective functioning of EDP, but also to the effective industrial transition and international collaboration.

Existing literature and policy reports on prioritisation focus on the categorisation of RIS3 priorities (degree of homogeneity, clustering or taxonomy of priorities) and less 
on their selection method (McCann and Ortega-Argilés 2016; Iacobucci and Guzzini 2016; Gianelle et al. 2019; Pavone et al. 2019). Evidence shows that there is a large variety of priority setting approaches among EU countries and among EU-regions (McCann and Ortega-Argilés 2016) although these can be grouped into coherent clusters of key activities (e.g. agro-food, life sciences etc.) (Pavone et al. 2019). According to the European Commission (EC 2012), priorities could be determined in terms of knowledge fields, subsystems within or across sectors, clusters, or technologies. Gianelle et al. (2019) based on their analysis of 39 policy documents from Italy and Poland argue that S3 priorities can be defined as a distinctive combination of four dimensions: (1) the sectors or value chains of primary interest for the intervention, (2) the transformative processes to be activated (technology applications), (3) the societal challenges to be addressed, and (4) the natural and/or cultural resources to be used. Classification methods may vary, ranging from sectoral classification to text mining or multi-dimensional analysis. This wide range of definitions/interpretations was due to a gap in the S3 theory of what an investment priority should be but also in the methodology guiding EDP.

Regardless of the actions taken for simplification and the widespread experimentation, a significant gap remains between theory and practice. The specifications of S3 make clear that the objective is diversification and industrial transformation towards higher added value activities. Diversification may be intra-industry, when research and innovation change and improve products and processes of an industry or inter-industry, when innovation leads to branching of an industry towards other sectors. Inter-industry diversification may be "related" to existing skills and know-how or "unrelated" towards new skills and know-how. Empirical evidence suggests that knowledge spillovers within a region, or smaller country, occur primarily among related sectors, and only to a limited extent among unrelated sectors. It is the related variety in a region that feeds branching out new activities from technologically related activities, not regional diversity nor regional specialisation per se (Boschma and Frenken 2011, p. 67). Therefore related variety can guide the selection of priority activities for inter-industry related diversification, but to our knowledge there isn't so far any theoretical guidance about the diversification of industries in the case of intra-industry change or interindustry un-related change.

This discussion brings EU countries and regions with three main challenges. The first refers to the actual identification of priority areas which reflects a clear policy direction. This selection should be based (a) on the detection of existing (knowledge, technological, market-related) capabilities and specialisations and (b) the selection of the most promising ones for potential diversification which are expected to unleash a highest potential for the future. The identification of such capabilities, especially through a collective process of EDP entails a high level of risk and should therefore be evidence based. This requires the employment of custom-made policy intelligence that draws upon the correct type of data depending on the country/region. The focus for example on patents underestimates other types of capabilities and is not relevant for less developed regions. Also, there is a delicate balance in the sense that priority areas should not be too general or too specific (Foray 2019).

The second challenge refers to the actual design of the strategy. Even after the selection of priorities how can a country/region best utilize funds in order to maximize 
the potential? What are the best actions that should be taken to unleash the potential of these sectors and how can theory orientate policy mix? The indication of bringing a critical level of investments on a few set of priorities might orientate funds towards ventures with limited beneficiaries which contradicts the actual notion of public policy.

These questions are accompanied by a methodology gap regarding the EDP granularity. Granularity allows defining the level of detail in modelling industries or decision-making processes. The greater the granulation, the deeper the level of detail and the better understanding of trends. Statistical data on industrial activities are given at four levels of granularity, classifying industries in 21 Sections, 88 Divisions, 272 Groups, and 615 Classes. We don't dispose any methodological guidance about the best granularity level to perform EDP. For instance, is it better to perform EDP at the level of industry sections, industry divisions, industry groups, or industry classes? The JRC application Eye@RIS3: Innovation Priorities in Europe which depicts S3 priorities across Europe shows that most member-states and regions have selected priorities (thus performed EDP) at the level of industry section or division. This is rather a low granularity EDP, which obstructs a clear outline of industrial diversification, because sections and divisions include a mixture of industrial activities with very different future trajectories. Dealing with the above three challenges is crucial for any country/region implementing their smart specialisation agenda, yet it becomes more daring for peripheral or less developed regions and for regions with low institutional capacity and advanced governance mechanisms, such as Greece.

\section{Ecosystem Discovery: A Survey for Greece}

We focus our analysis in the thirteen NUTS-2 level Greek regions. Greece is a peripheral country in the EU with below average GDP per capita and only a moderate innovator. The country, which is mainly based on tourism and the overall services sector, has one of the lowest levels of patent applications in Europe. Given the low levels of growth and the significant effects of the recent economic crisis in the country's economy, Smart Specialisation has a higher significance as a chance for achieving cohesion and catching up more developed countries.

Stage 1 of our survey deals with the prioritisation challenge by adopting a method based on data than theory. We start from the statement that all industries of a country or region have potential for diversification and growth. Our intention is to test the feasibility of this approach for Greece. Instead of selecting a few industries and perform EDP in them, we examine the most important industries per region, in terms of size and specialisation. Two reasons justify this orientation of work: (a) the widely accepted S3 principle for place-specific innovation strategy or "one-size-does-not-fit-all", which suggests that the most robust theoretical prediction should be assessed with placespecific data, and (b) the probability of finding innovative solutions in less expected activities, a trend outlined by many aspects of innovation theory, such as the probabilistic and non-deterministic character of innovation, serendipity in innovation, and innovation outcomes by chaotic systemic combinations. 
We test the feasibility of performing EDP at the level of NACE industry groups (272 groups) for all important industry groups per region of Greece, in four steps (a) starting with the regional distribution of industrial activity in Greece at NACE group level, (b) defining the most important industry groups per region, (c) defining the top-10 industry groups in the 13 regions of Greece, (d) assessing the diversity of industry groups in all regions of Greece and the needs for EDP exercises. More specifically, after listing industry groups per region, we produced four ordered lists of industry groups per region, by number of companies, number of employees, location quotient on companies, and location quotient on employment (top-40 industry groups). These lists which sort industry groups per size and specialization were used to select the first ten industry groups by size and specialisation. Top-10 industry groups in the 13 regions of Greece (Table Annex 2) belong to 51 categories, of which 26 categories appear in more than one region and 25 in one region only. These 26 industry groups hold 105 out of $130(81 \%)$ top-10 positions in all regions of Greece. This finding indicates that with EDP at 51 industry groups we can cover all most important industries of Greece, while with EDP at 26 industry groups we can cover $81 \%$ of most important industry groups in Greece.

Stage 2 is a complementary survey which deals with the discovery challenge. Having included all important industry groups in the EDP process, our intention is to assess the conditions for diversification and transformation per industry group. The questions that appear here are "which is the potential for successful EDP in each of those 51 industry groups?", "should we perform EDP in all cases or some industries don't meet the conditions for a successful outcome?", "can we state common problems to address through EDP in each and every of the 51 industry groups?", "is there critical innovation capacity and motivation for innovation in all 51 groups?" and "is there potential for ecosystem building for the benefit of all companies of an industry group?".

To answer these questions, we undertook a four-step study. We started with (a) an interview-based survey with business stakeholders and experts in the 13 regions of Greece to identify industry groups with potential for ecosystem building, (b) continued with a desk study of business and challenges per selected industry group (25 out of the 51 industries), (c) a survey on research and innovation demand per industry group, and (d) ended up identifying challenges and platforms that may orchestrate companies towards common goals and ecosystems. The latter is particularly important when it comes to maintaining EDP as a public policy exercise that promotes collective rather than individual goals.

We use the concept of platform and platform-ecosystem to bring together companies and stakeholders under the same challenges and objectives. By examining growth and innovation data and trends to define challenges, platforms, and ecosystems per industry group, we try to re-assess prioritisation with respect to capacity to define common problems and platforms for ecosystem building. Priority activities are those where a common problem allows for defining a platform, which in turn enables the transformation of the industry group. We examine growth and innovation trends per industry group and the potential for ecosystem building over platforms for industrial transformation. In such platform-based ecosystems, ecosystems that don't pre-exist but are formed over platforms, which orchestrate both the supply and demand side of the respective industry (see Fig. 1). 


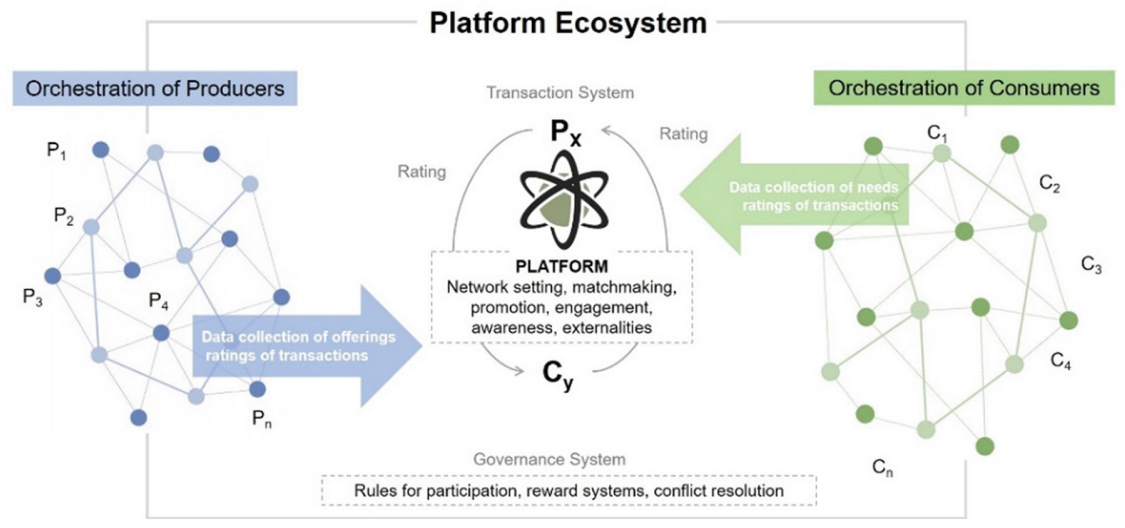

Fig. 1. Platforms driving the emergence of ecosystems.

Our analysis revealed about 25-40 industry groups which can cover the most important economic activities. Out of the 25 most important industry groups, 21 (85\%) were included in the respective RIS3 priority domain with significant differences however in the level of analysis. Most of the identified industries face common challenges which reflect their problems in dealing with exports, eco-labels, new products, waste management, technology support from competence centres. Based on these challenges we identify 22 industry groups in which business and innovation ecosystems can be created under the guidance and orchestration of well-designed platforms (Table 1).

Our analysis revealed about 25-40 industry groups which can cover the most important economic activities. Out of the 25 most important industry groups, 21 (85\%) were included in the respective RIS3 priority domain with significant differences however in the level of analysis. Most of the identified industries face common challenges which reflect their problems in dealing with exports, eco-labels, new products, waste management, technology support from competence centres. Based on these challenges we identify 22 industry groups in which business and innovation ecosystems can be created under the guidance and orchestration of well-designed platforms (Table 1).

Platforms and value chains can connect companies around such common challenges forming orchestrated ecosystems (Kakderi et al. 2018). The types of platforms identified are (i) market-driven, with emphasis on demand, market access, branding, product promotion; (ii) product-driven, with emphasis on new products, smart products, quality, certification; (iii) technology-driven, with emphasis on research, production processing, supply chain integration; (iv) infrastructure-driven, with emphasis on physical, institutional, equipment, tools and (v) materials-driven, with emphasis on new materials, raw material, waste, and materials recycling. The type of ecosystems these platforms can sustain is regional and national. The majority are mature ecosystems in traditional business activities, while there is also a small number of emerging ecosystems (20\%) in ICT, pharmaceutical and research services. Also, we observe an 
Table 1. Industry groups and ecosystems key features

\begin{tabular}{|c|c|c|c|c|c|c|c|c|}
\hline Region & $\begin{array}{l}\text { Industry group / } \\
\text { ecosystem }\end{array}$ & $\begin{array}{l}\text { Included } \\
\text { in RIS3 } \\
2014- \\
2020 \\
\text { priorities }\end{array}$ & $\begin{array}{l}\text { Size of } \\
\text { ecosystem }\end{array}$ & $\begin{array}{l}\text { Mature or } \\
\text { emerging } \\
\text { ecosystem }\end{array}$ & $\begin{array}{l}\text { Research } \\
\text { and } \\
\text { innovation } \\
\text { demand }\end{array}$ & $\begin{array}{l}\text { Initial identification of } \\
\text { innovation platform }\end{array}$ & $\begin{array}{l}\text { National/regional } \\
\text { ecosystem }\end{array}$ & $\begin{array}{l}\text { EDP for } \\
\text { platform } \\
\text { design }\end{array}$ \\
\hline \multirow[t]{3}{*}{$\begin{array}{l}\text { East } \\
\text { Macedonia } \\
\text { Thrace }\end{array}$} & $\begin{array}{l}22.2 \\
\text { Manufacture of } \\
\text { plastics }\end{array}$ & Yes & Small & Mature & Medium & New product/materials & Regional & Yes \\
\hline & $\begin{array}{l}23.7 \text { Cutting, } \\
\text { shaping of } \\
\text { stone }\end{array}$ & Yes & Large & Mature & Medium & Brand/byproducts & National & Yes \\
\hline & $\begin{array}{l}26.2 \\
\text { Manufacture of } \\
\text { computers }\end{array}$ & Yes & Small & Emerging & High & No & Regional & No \\
\hline \multirow[t]{3}{*}{$\begin{array}{l}\text { Central } \\
\text { Macedonia }\end{array}$} & $\begin{array}{l}10.3 \text { Processing } \\
\text { fruit and } \\
\text { vegetables }\end{array}$ & Yes & Large & Mature & High & Brand/packaging & National & Yes \\
\hline & $\begin{array}{l}14.1 \\
\text { Manufacture of } \\
\text { wearing apparel }\end{array}$ & Yes & Large & Mature & Medium & Brand/design & Regional & Yes \\
\hline & $\begin{array}{l}25.1 \\
\text { Manufacture of } \\
\text { structural metal } \\
\text { products }\end{array}$ & Yes & Large & Mature & Medium & Materials & Regional & Yes \\
\hline \multirow[t]{2}{*}{$\begin{array}{l}\text { West } \\
\text { Macedonia }\end{array}$} & $\begin{array}{l}16.2 \\
\text { Manufacture of } \\
\text { products of } \\
\text { wood }\end{array}$ & No & Large & Mature & Low & Brand/eco-quality & National & Yes \\
\hline & $\begin{array}{l}14.2 \\
\text { Manufacture of } \\
\text { fur }\end{array}$ & Yes & Large & Mature & Low & Export & Regional & Yes \\
\hline \multirow[t]{2}{*}{ Epirus } & $\begin{array}{l}\text { 10.1 Processing } \\
\text { of meat }\end{array}$ & Yes & Medium & Mature & Medium & Brand/packaging & National & Yes \\
\hline & $\begin{array}{l}10.5 \\
\text { Manufacture of } \\
\text { dairy products }\end{array}$ & Yes & Large & Mature & High & Brand/packaging & National & Yes \\
\hline \multirow[t]{2}{*}{ Thessaly } & $\begin{array}{l}22.1 \\
\text { Manufacture of } \\
\text { rubber products }\end{array}$ & No & Small & Emerging & Low & No & Regional & No \\
\hline & $\begin{array}{l}31.0 \\
\text { Manufacture of } \\
\text { furniture }\end{array}$ & No & Large & Mature & Low & Commercial infrastr. & National & Yes \\
\hline St Ellada & $\begin{array}{l}24.2 \\
\text { Manufacture of } \\
\text { tubes of steel }\end{array}$ & Yes & Small & Mature & Low & New product & Regional & No \\
\hline $\begin{array}{l}\text { Ionian } \\
\text { Islands }\end{array}$ & $\begin{array}{l}79.1 \text { Travel and } \\
\text { tour operator } \\
\text { activities }\end{array}$ & Yes & Large & Mature & High & New products & National & Yes \\
\hline \multirow[t]{3}{*}{ Attica } & $\begin{array}{l}90.0 \text { Creative, } \\
\text { arts activities }\end{array}$ & Yes & Large & Mature & High & Digital infrastr. & National & Yes \\
\hline & $\begin{array}{l}62.0 \text { Computer } \\
\text { programming }\end{array}$ & Yes & Large & Emerging & High & Market/infrastr & Regional & Yes \\
\hline & $\begin{array}{l}21.1 \\
\text { Manufacture of } \\
\text { pharmaceutical } \\
\text { products }\end{array}$ & Yes & Small & Emerging & High & New products & Regional & Yes \\
\hline \multirow[t]{2}{*}{$\begin{array}{l}\text { Western } \\
\text { Greece }\end{array}$} & $\begin{array}{l}03.2 \\
\text { Aquaculture }\end{array}$ & Yes & Medium & Mature & Medium & Brand/product & National & Yes \\
\hline & $\begin{array}{l}10.9 . \\
\text { Manufacture of }\end{array}$ & No & Medium & Mature & Medium & Production/chain & National & Yes \\
\hline
\end{tabular}


Table 1. (continued)

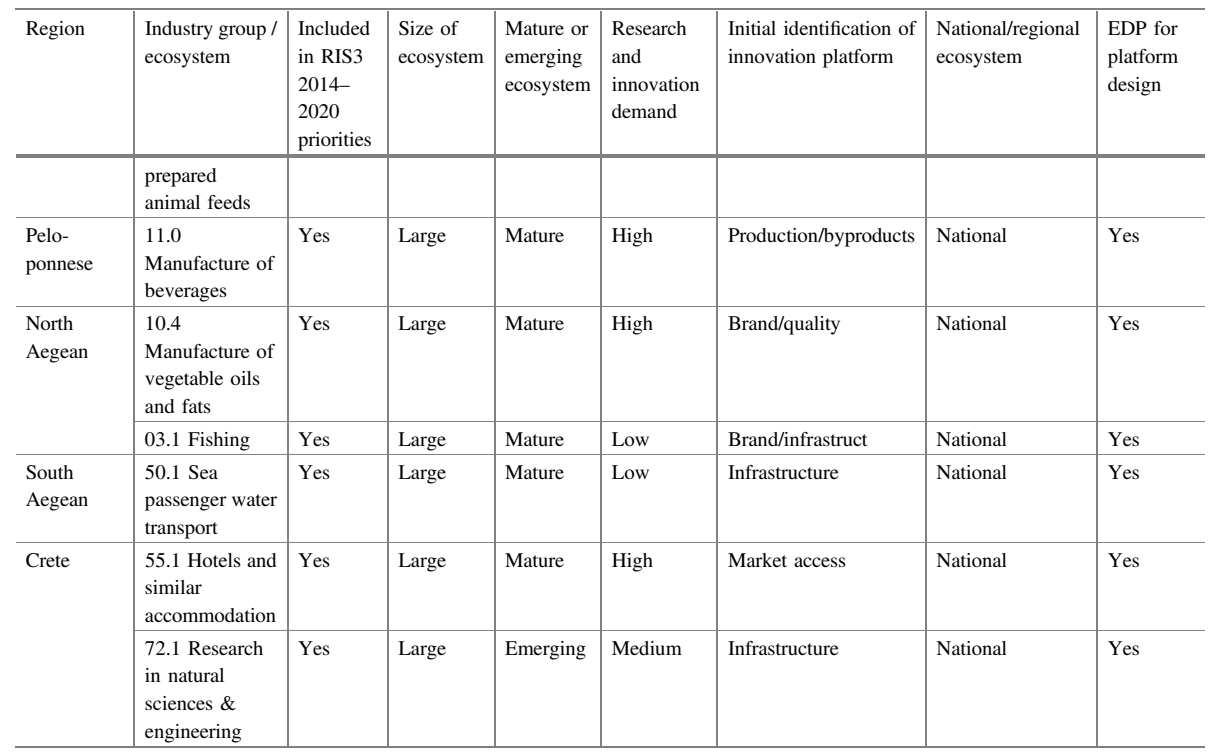

equal distribution of small with less than 100 companies in the region of reference and large ecosystems with more companies.

The above observations may clarify the inclusion of industry groups studied in EDP exercises. In $22 / 25(88 \%)$ of cases, this preliminary investigation documents that EDP conditions are met and EDP should follow to reveal the features of platforms and other commons for ecosystem building. In these 22 cases, there is substantial evidence that EDP may drive actions proper to public policy, promoting collective rather than individual interests. All national ecosystems should be included for EDP, while 3 out of 10 regional cases do not meet the conditions for EDP, due to low innovation demand, small number of companies in the group, and mature than emerging industries.

\section{Re-orienting EDP Towards Platforms and Ecosystems}

This exercise revealed some important findings for Greece but also indicates some policy recommendations for other territories. Industry platforms address common challenges of companies belonging to an industry group and create favourable conditions for setting up business and innovation ecosystems (Panori et al. 2020). In every top-10 industry group we have identified production, trade, technology and environmental challenges. With respect to these challenges, EDP should focus on the design of platforms that drive the formation of business ecosystems.

The definition of common challenges and potential platforms is a pathway to platform-ecosystems. Research in the field of platforms shows that "industry platforms are technological building blocks (that can be technologies, products, or services) that 
act as a foundation on top of which an array of firms, organized in a set of interdependent firms (sometimes called an industry "ecosystem"), develop a set of interrelated products, technologies and services" Gawer (2010; 287). Equally, platforms can be understood as collaborative business models based on technology that engender ecosystems. A platform is "a plug-and-play business model that allows multiple participants (producers and consumers) to connect to it, interact with each other and create and exchange value" (Castellani, n.a.).

Platform-based ecosystems are created when an organisation launches a platform that becomes the foundation for products and services of other companies. Gawer and Cusumano (2002) call this relationship "platform leadership", a strategy that enables companies to exert influence over the direction of innovation in an industry, by engaging other firms in a joint effort for complementary products. Industry-wide platforms offer resources that third party organisations can use to develop their own complementary products, technologies, or services. They enable the creation of business ecosystems and has a disruptive network effect in many industries. They are foundations for setting up ecosystems of organisations that share resources, knowledge or access to markets (Gawer and Cusumano 2014). Working with an industry-wide platform typically results in a two-part structure: on the one side, there is the specific solution that is hosted on the platform, and on the other side, there is the platform with its infrastructure, hardware, software and data which communicate with the hosted solutions and organise collaboration according to established procedures.

Platforms must be designed as service providers. Their detailed design must define the model of service provision, the providers, services, and users, as well as the business model, the service operation model, and the quality model of provided services assessment. Failure of defining a sustainable service model is equal to EDP failure and no further policy support to the respective industry group should be provided. Platforms may be physical, institutional, infrastructure and digital. They can be market-driven, product-driven, technology-driven, infrastructure-driven or materialsdriven. Platforms providing services for market making (access, branding, promotion), product development (innovation, quality, certification, standardisation) and technology development (materials, processing, value chain optimisation) are mostly needed to address growth and innovation challenges of business ecosystems. They give birth to business ecosystems created around common challenges. Platforms and ecosystems guarantee the public character of policy mix and actions deriving from EDP as they serve common needs of an industry group than individual trajectories and interests of companies. Such ecosystems do not need to exist prior to the platform, since it acts as an anchor orchestrating complementors. Ecosystems can be created in each and every industry group around a challenge and common assets that may deal with the challenge. The starting point is to recognize some form of externalities (conditions outside the market and inter-firm competition) and how a platform can engage the companies of the industry group and offer advantages in dealing with the challenges they face. It may be an e-commerce platform, a common quality control laboratory, a common treatment of production waste. It may be also a service developed by a group of companies, which is needed, without being a field of competition. 


\section{References}

Balland, P.-A., Boschma, R., Crespo, J., Rigby, D.L.: Smart specialization policy in the European Union: relatedness, knowledge complexity and regional diversification. Reg. Stud. 53(9), 1252-1268 (2019). https://doi.org/10.1080/00343404.2018.1437900

Boschma, R., Frenken, K.: 14 technological relatedness, related variety and economic geography. In: Handbook of Regional Innovation and Growth, p. 187 (2011)

Boschma, R.: Relatedness as driver behind regional diversification: a research agenda. Reg. Stud. 51(3), 351-364 (2017)

Committee of the Regions (CoR). Regions and Cities call for a new Smart Specialisation built on interregional collaboration, 16.05.2018, Press Release (2018). https://cor.europa.eu/en/news/ Pages/Regions-and-cities-call-for-a-new-Smart-Specialisation-2-0-built-on-interregionalcooperation.aspx. Accessed 18 Feb 2020

European Commission. Frequently asked questions on RIS3 (2012). Accessed from http:// s3platform.jrc.ec.europa.eu/faqs-on-ris3

Foray, D.: From smart specialisation to smart specialisation policy. Eur. J. Innov. Manage. 17(4), 492-507 (2014). https://doi.org/10.1108/EJIM-09-2014-0096

Foray, D.: In response to 'Six critical questions about smart spezialisation'. Eur. Plan. Stud. 27 (10), 2066-2078 (2019)

Gawer, A.: The organization of technological platforms. In: Technology and Organization: Essays in Honour of Joan Woodward. Emerald Group Publishing Limited (2010)

Gawer, A., Cusumano, M.A.: Industry platforms and ecosystem innovation. J. Prod. Innov. Manag. 31(3), 417-433 (2014)

Gianelle, C., Kyriakou, D., Cohen, C., Przeor, M.: Implementing Smart Specialisation: A Handbook (EUR 28053 EN). European Commission, Brussels (2016). https://doi.org/10. $2791 / 53569$

Gianelle, C., Guzzo, F., Mieszkowski, K.: Smart specialisation: what gets lost in translation from concept to practice? Reg. Stud., 1-12 (2019). https://doi.org/10.1080/00343404.2019. 1607970

Griniece, E., Panori, A., Kakderi, C., Komninos, N. Reid, A.: Methodologies for smart specialisation strategies: a view across the EU regions. In: International Conference for Entrepreneurship, Innovation, and Regional Development (ICEIRD 2017), Thessaloniki (2017)

Hassink, R., Gong, H.: Six critical questions about smart specialization. Eur. Plan. Stud. 27(10), 2049-2065 (2019)

Iacobucci, D.: Designing and implementing a smart specialisation strategy at regional level: Some open questions. Sci. Reg. 13(1), 107-126 (2014)

Iacobucci, D., Guzzini, E.: Relatedness and connectivity in technological domains: missing links in S3 design and implementation. Eur. Plan. Stud. 24(8), 1511-1526 (2016)

Kakderi, C., Psaltoglou, A., Fellnhofer, K.: Digital platforms and online applications for user engagement and collaborative innovation. In: The 20th Conference of the Greek Society of Regional Scientists (2018)

Komninos, N., Musyck, B., Iain Reid, A.: Smart specialisation strategies in south Europe during crisis. Eur. J. Innov. Manage. 17(4), 448-471 (2014)

Komninos, N., Kakderi, C., Panori, A., Garcia, E., Fellnhofer, K., Reid, A., Cvijanović, V., Roman, M., Deakin, M., Mora, L. Reid, A.: Intelligence and co-creation in Smart Specialisation Strategies: Towards the next stage of RIS3. Online S3 White Paper (2018). https://www.onlines3.eu/wp-content/onlines3-files/22\%20Intelligence\%20and\%20cocreation\%20in\%20Smart\%20Spec.pdf 
Kroll, H.: Efforts to implement smart specialization in practice-leading unlike horses to the water. Eur. Plan. Stud. 23(10), 2079-2098 (2015). https://doi.org/10.1080/09654313.2014. 1003036

Kyriakou, D., Palazuelos Martinez, M., Periáñez-Forte, I., Rainoldi, A.: Governing Smart Specialisation. Routledge, London (2017)

Landabaso, M., Valdaliso, J.M., Magro, E., Navarro, M., Aranguren, M.J., Wilson, J.R.: Path dependence in policies supporting smart specialisation strategies. Eur. J. Innov. Manage. 17, 390-408 (2014). https://doi.org/10.1108/EJIM-12-2013-0136

McCann, P., Ortega-Argiles, R.: Smart specialization, regional growth and applications to European Union cohesion policy. Reg. Stud. 49(8), 1291-1302 (2015). https://doi.org/10. 1080/00343404.2013.799769

McCann, P., Ortega-Argilés, R.: The early experience of smart specialization implementation in EU cohesion policy. Eur. Plan. Stud. 24(8), 1407-1427 (2016). https://doi.org/10.1080/ 09654313.2016.1166177

Official Journal of the European Union (OJ). Regulation (EU) No 1303/2013 of the European Parliament and of the Council of 17 December 2013 (2013)

Panori, A., Kakderi, C., Komninos, N., Fellnhofer, K., Reid, A., Mora, L.: Smart systems of innovation for smart places: Challenges in deploying digital platforms for co-creation and data-intelligence. Land Use Policy, 104631 (2020)

Panori, A., Komninos, N., Kakderi, C., Fellnhofer, K.: Smart specialisation strategies: an online platform for strategy design and assessment. In: Kabashkin, I., Yatskiv, I., Prentkovskis, O. (eds.) RelStat 2017. LNNS, vol. 36, pp. 3-16. Springer, Cham (2018). https://doi.org/10. 1007/978-3-319-74454-4_1

Pavone, P., Pagliacci, F., Russo, M., Giorgi, A.: R\&I smart specialisation strategies: classification of EU regions' priorities. Results from automatic text analysis. DEMB Working Paper Series No. 148 (2019)

Piatkowski, M., Szuba, T., Wolszczak, G.: Review of National and Regional Research and Innovation Strategies for Smart Specialization (RIS3) in Poland. World Bank Group, Washington (2014)

Reid, A., Komninos, N., Sanchez, J., Tsanakas, P.: RIS3 National Assessment: Greece. Smart Specialisation as a Means to Foster Economic Renewal. Report to the European Commission, DG Regional Policy. European Commission, Brussels (2012)

Open Access This chapter is licensed under the terms of the Creative Commons Attribution 4.0 International License (http://creativecommons.org/licenses/by/4.0/), which permits use, sharing, adaptation, distribution and reproduction in any medium or format, as long as you give appropriate credit to the original author(s) and the source, provide a link to the Creative Commons license and indicate if changes were made.

The images or other third party material in this chapter are included in the chapter's Creative Commons license, unless indicated otherwise in a credit line to the material. If material is not included in the chapter's Creative Commons license and your intended use is not permitted by statutory regulation or exceeds the permitted use, you will need to obtain permission directly from the copyright holder.

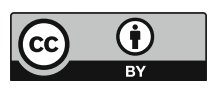

